\title{
The Burden of Proof in Philosophical Persuasion Dialogue
}

\author{
Conny Rhode ${ }^{1}$
}

Published online: 27 May 2017

(C) The Author(s) 2017. This article is an open access publication

\begin{abstract}
Dialogical egalitarianism is the thesis that any proposition asserted in dialogue, if questioned, must be supported or else retracted. Dialogical foundationalism is the thesis that some propositions are privileged over this burden of proof, standing in no need of support unless and until support for their negation is provided. I first discuss existing arguments for either thesis, dismissing each one of them. Absent a successful principled argument, I then examine which thesis it is pragmatically more advantageous to adopt in analytic philosophical dialogue. This requires identifying the goal of such dialogue, to the attainment of which the thesis would be so advantageous. To identify this goal, I draw on Douglas Walton's typology of dialogues for an analysis of the types of dialogue of 110 representatively selected journal articles in current analytic philosophy. 95\% of articles are found to instantiate persuasion dialogue. In light of the thus prevalent goal of persuading one's opponent, I argue that the adoption of dialogical egalitarianism in analytic philosophical dialogue is pragmatically inescapable.
\end{abstract}

Keywords Burden of proof · Commitment · Foundationalism · Metaphilosophy · Persuasion dialogue

\section{Egalitarianism Versus Foundationalism}

According to dialogical egalitarianism, any proposition asserted in dialogue, if questioned, must be supported or else retracted. ${ }^{1}$ Hence the burden of proof for any asserted and questioned proposition lies upon the asserting party. According to

\footnotetext{
${ }^{1}$ Criteria of sufficiency of support are extraneous to the present considerations.

Conny Rhode

conny.rhode@outlook.com

1 Department of Philosophy, University of York, York YO10 5DD, UK
} 
dialogical foundationalism, at least some propositions are privileged over this burden, such that the asserting party need only support the proposition if and when the questioning party has defended her challenge by providing support for the proposition's negation. ${ }^{2}$ In effect, if you assert some putatively privileged proposition $\mathrm{P}$, such as The sky is blue by day, and another party to the dialogue questions whether $\mathrm{P}$ (without providing support for $\neg \mathrm{P}$ ), then you are thus required to defend your commitment to $\mathrm{P}$ under dialogical egalitarianism but not under dialogical foundationalism. If, however, the proposition $\mathrm{P}$ that you assert is not putatively privileged and is being questioned (without provision of support for $\neg \mathrm{P}$ ), then you are required to defend your commitment to $\mathrm{P}$ under either thesis. For a definition of the privileged status of $\mathrm{P}$, assume that party $a$ to dialogue $\delta$ commits to some proposition $\mathrm{P}$ in $\delta$ (e.g. by asserting that $\mathrm{P}$ ) and party $b$ to dialogue $\delta$ commits to neither $\mathrm{P}$ nor $\neg \mathrm{P}$ in $\delta$ (e.g. by questioning whether $\mathrm{P}$, without providing support for $\neg \mathrm{P}$ ). Then $\mathrm{P}$ is privileged just in case it is true that: $a$ is required to provide support for or to retract her commitment to $\mathrm{P}$ in $\delta$ if and only if $b$ provides support for $\neg \mathrm{P}$ in $\delta{ }^{3}$ Thus, dialogical foundationalism affirms and dialogical egalitarianism rejects the existence of privileged propositions and of the resultant uneven distribution of the burden of proof.

Though rarely made explicit in substantive analytic philosophical debates, ${ }^{4}$ dialogical foundationalism has surfaced particularly in recent disputes in philosophical methodology. Its ascription of privileged status is exemplified in Roderick Chisholm's contention that '[a]ny philosophical theory which is inconsistent with any of [the propositions of common sense] is prima facie suspect. The burden of proof will be upon the man [sic] who accepts any such theory' (1976: 18). Chisholm's advocacy of privileged status for common-sense propositions is echoed in George Bealer's remark that '[u]nless and until a reason for departing from this standard practice is produced, we are entitled-indeed, obligated - to continue using intuitions as evidence' (1996: 30 n. 15; emphasis added). Timothy Williamson holds the closely related view that 'it would be foolish to change a well-established methodology [like philosophers' use of thought experiments] without serious evidence that doing so would make the discipline better rather than worse' (2011: 217). Chisholm, then, claims privileged status for any common-sense proposition, while Bealer and Williamson claim privileged status for any proposition that sanctions some 'standard' or 'well-established' evidential procedure, including in particular the procedures of evidentially employing intuitions or thought experiments. If we assume that $\mathrm{M}$ may be any proposition affirming the evidential value of common sense, intuitions, thought experiments or another a priori source of evidence, then Chisholm, Bealer and Williamson in effect claim that $M$ is dialogically privileged.

\footnotetext{
2 These competing theses were first distinguished by Michael Rescorla (2009a).

${ }^{3}$ Propositions that, due to their privilege, are in no need of support in $\delta$ unless and until support for their negation is provided in $\delta$ should not be confused with propositions that, due to support already provided in $\delta$, are in no need of further support in $\delta$ unless and until support for their negation is provided in $\delta$. Only the former status depends upon dialogical foundationalism.

${ }^{4}$ For convenience, I subsequently frequently employ 'philosophy' and cognate terms in substitution of 'analytic philosophy' and cognate terms.
} 
Indeed, this privileged status of $\mathrm{M}$ appears to be implicitly presumed in substantive philosophical debates relying on some or all of these putative sources of evidence. Most philosophers will be aware that the evidential value of common sense, intuitions, thought experiments and other a priori sources of evidence has of late been questioned, as well as that no definitive resolution of these challenges has been found. Yet most philosophers continue regardless in their evidential employment of some or all of these challenged a priori sources of evidence, thereby continuing to accept $\mathrm{M}$. That is to say, most philosophers continue to accept $M$ in their substantive debates even despite the fact that $M$ has been questioned and that these questions are still awaiting unchallenged resolution in M's favour. This continued acceptance of $\mathrm{M}$ is incompatible with dialogical egalitarianism, which would require in this situation that acceptance of $M$ (and equally rejection of $M$ ) in dialogue be suspended. But it is compatible with dialogical foundationalism, which permits treating $\mathrm{M}$ as privileged by not placing the burden of proof for $\mathrm{M}$ upon the party that asserts or continually accepts $M$ but instead placing the burden of proof for $\neg \mathrm{M}$ upon any party that denies or even just questions $\mathrm{M}$. In their substantive debates, so it seems, most philosophers take $M$ to be privileged, seeing as they continue their employment of the sources of evidence sanctioned by $\mathrm{M}$ regardless of recent challenges to $M$. In taking $M$ to be privileged, most philosophers are thus presuming either the truth or, minimally, the adoption of dialogical foundationalism. ${ }^{5}$ Much substantive philosophical work thus seems to depend, perhaps even vitally so, upon the adoption of dialogical foundationalism.

I will presently argue, however, that philosophers are pragmatically required to adopt dialogical egalitarianism, with the notable implication that the burdens of proof recently placed upon the employment of a priori methods in philosophical dialogue cannot be evaded and must instead be met. After briefly elucidating the characterisation of the competing theses as dialogical (Sect. 2), I discuss and dismiss existing arguments for either thesis (3). To help resolve the debate, I then present quantitative research indicating that analytic philosophical dialogues are predominantly aimed at persuading one's opponent (4-5). This observed goal renders the adoption of dialogical egalitarianism in analytic philosophy prudently inescapable (6), though it does not yield any similar pragmatic recommendation for dialogues outside of analytic philosophy. I close by addressing two potential objections (7).

\section{Commitments and Their Locations}

For any proposition $\mathrm{P}$, I can make various commitments towards P. Leaving aside commitments regarding the goodness of $\mathrm{P}$ (made, for instance, when hoping that $P$ or fearing that $P$ ), I can make either or neither of two commitments regarding the truth-value of $\mathrm{P}$, exemplified when believing that $P$ or disbelieving that $P$. Absent

\footnotetext{
5 Note that dialogical foundationalism with regard to $\mathrm{M}$ implies dialogical foundationalism, but not vice versa. Conversely, dialogical egalitarianism implies dialogical egalitarianism with regard to M, but not vice versa.
} 
either of these, I may be wondering whether $P$. Each of these commitments exemplified here is made in, or 'located' in, attitudinal states. Call them, therefore, attitudinal commitments. As these examples illustrate, I can commit attitudinally to $\mathrm{P}$, to $\neg \mathrm{P}$, or to neither $\mathrm{P}$ nor $\neg \mathrm{P}$. Apart from their attitudinal location, however, commitments regarding the truth-value of $\mathrm{P}$ can also be made in dialogue. I can, for instance, assert that $P$, deny that $P$, or ask/question whether $P$, thus committing dialogically to $\mathrm{P}$, to $\neg \mathrm{P}$, or to neither $\mathrm{P}$ nor $\neg \mathrm{P}$. ${ }^{6}$ This separation between attitudinal and dialogical truth-value commitments is founded in a distinction between targets, or recipients, of such commitments. ${ }^{7}$ A dialogical truth-value commitment is directed towards, or made to, someone else (lest it would not be located in a dialogue), whereas an attitudinal truth-value commitment is directed towards or made to oneself (being itself inaccessible to others). Strictly, then, the target of any of one's own truth-value commitments either is or is not identical with oneself, thus dividing commitments exclusively and exhaustively into those made in attitude and those made in dialogue.

Given this separation, no attitudinal commitment necessitates any dialogical commitment, nor vice versa (cf. Rescorla 2009b; Aijaz, McKeown-Green and Webster 2013). I can, as a matter of fact, deny that Knowledge is a socially constructed kind yet wonder whether this proposition might not be true after all. Equally, I can believe that Implicit biases contribute significantly to philosophy's relative demographic homogeneity without asserting the same to an interlocutor, most obviously when no potential interlocutor is present. While most people's dialogical truth-value commitments correspond to their attitudinal truth-value commitments in most circumstances, that correspondence is contingent. It does not indicate any logically necessary connection between dialogical and attitudinal commitments.

This independence of commitments in different locations is curtailed, one might hold, by norms prescribing permissible combinations of commitments. The norm that One ought not to lie, for instance, proscribes making a dialogical commitment without having the corresponding attitudinal commitment. Such norms, however, are beside the point here. There may well exist social, ethical, epistemic, linguistic, rational or other prescriptions regarding the appropriateness of, for instance, asserting that $\mathrm{P}$ without believing that $\mathrm{P}$. But here I merely seek to emphasise that any such prescription would connect two commitment locations that are otherwise logically independent, such that no truth-value commitment in one location by itself necessitates any truth-value commitment in the other location. I emphasise this perhaps uncontroversial independence in order to subsequently concentrate solely upon commitments in philosophical dialogue - and specifically upon the requirement to support any of one's dialogical commitments when they are challenged, as contested between dialogical egalitarianism and dialogical foundationalism.

\footnotetext{
${ }^{6}$ It is of course possible to assert that $\mathrm{P}$ (or deny that $\mathrm{P}$ or ask whether $\mathrm{P}$ ) without engaging in a dialogue, e.g. by assertively uttering $\mathrm{P}$ to oneself. That notwithstanding, I subsequently employ 'asserting that P' and cognate expressions solely to denote 'committing dialogically to the truth of $\mathrm{P}$ ' and cognate expressions, and correspondingly with regard to the foregoing examples of the other dialogical and attitudinal commitments.

7 The terminology for this separation, 'attitudinal' versus 'dialogical', is adapted from Aijaz et al. (2013).
} 


\section{Distributing the Burden of Proof}

As introduced above, dialogical foundationalism states that some propositions are privileged over the burden of proof imposed by their mere questioning, while dialogical egalitarianism states that no proposition is so privileged. In the debate between advocates of these two theses in philosophy, variations of three arguments have found employment-all in their basic form directed against dialogical egalitarianism. These three arguments invoke, respectively, practical need, the threat of scepticism, and putatively foundational propositions. I will discuss them in turn.

The assessment of alternative courses of action is frequently based on incomplete information, yet a decision between the alternatives must nonetheless be taken. In a criminal trial, deciding whether and how to punish a defendant cannot be postponed until sufficient evidence is available for the conclusive proof of guilt or innocence, not least since the potentially life-long waiting time (in custody or freedom) may itself constitute punishment. Instead, decision-making to guide action is often based on stipulated default outcomes, and thus on presumptions, placing the burden of proof, not upon the party in a dialogue that asserts, but upon the party that remains non-committed towards (or denies) the proposition expressing the default outcome. In criminal trials this is exemplified by the presumption of innocence, which, for the deliberation of a verdict and potential sentence, prescribes the default outcome of acquittal and non-punishment. Practical need thus seems to give rise to dialogical foundationalism in criminal legal proceedings, as well as in various other contexts. Unless philosophy is relevantly disanalogous, dialogical foundationalism would be equally warranted in philosophy. Yet philosophy is indeed relevantly disanalogous. The failure to resolve a philosophical question is of scarce import to any real-life and thus relatively urgent problem. As Brian Treanor (2006) aptly remarked: 'I'm a professor of philosophy, not a cardiac surgeon. How urgent can it be?' Nothing of non-academic value will be jeopardised by failure to answer a philosophical question; hence practical need does not warrant the adoption of presumptions in order to preclude such failure in philosophical dialogue (cf. Sander 2003: 84; Dyke 2013: 174). Though there may certainly be benefits from answering a philosophical question, there is no practical need for an answer (despite grant applications sometimes suggesting otherwise).

Perhaps the adoption of presumptions in philosophical dialogue may instead be warranted by cognitive need, that is, the need for discovering truths or generating knowledge. ${ }^{8}$ This warrant would suggest that a presumption is functionally equivalent to a key thesis accepted within a Kuhnian paradigm (Kuhn 1962). Indeed, according to Neil Levy (2003), the work of Frege and Russell is treated as the defining exemplar of analytic philosophy, or as the paradigm in Kuhn's narrower sense of that word, while each sub-discipline or research programme within analytic philosophy is characterised additionally by its own exemplars. Exemplars provide a field of research with its key methodological and ontological theses that underlie and significantly facilitate all subsequent work within that field.

\footnotetext{
${ }^{8}$ I am grateful to an anonymous reviewer for this journal, whose comments gave rise to the present point.
} 
Such key theses effectively function as presumptions, whose unquestioned acceptance in a given field is warranted at least by the need for generating knowledge. As such, cognitive need may seem to warrant the adoption of presumptions, and thus of dialogical foundationalism, in analytic philosophical dialogue. That, however, is not the case. If knowledge, as generated in analytic philosophy, was regarded as an end in itself, then it is unclear why there would be any need for the attainment of that end. That is, it is unclear why the generation of philosophical knowledge or the discovery of philosophical truth would be needed. If, on the other hand, analytic philosophical knowledge was regarded as a means to some other end (akin to medical or geological knowledge), then this argument from cognitive need would collapse into the above argument from practical need. (Moreover, as I will show below, analytic philosophical dialogue is not in fact aimed at the generation of knowledge, and would thus in any case fail to satisfy any cognitive need.) Either way, the adoption of presumptions in current analytic philosophical dialogue is not warranted by cognitive need, nor, as shown above, is it warranted by practical need.

A more popular argument for dialogical foundationalism holds that dialogical egalitarianism implies global epistemological scepticism and must thus be rejected (Rescorla 2009b: 48). According to this argument, the requirement to provide support for every single dialogical truth-value commitment I make would launch an infinite regress of supporting propositions, leaving me unable to justify any proposition at all and thus forcing me to accept global scepticism. Though this argument may appear prima facie plausible, it fails in at least three respects. First, it presupposes that global scepticism is unacceptable, thus begging the question against dialogical egalitarians who are also global sceptics, viz. the Pyrrhonians. ${ }^{9}$ Second, the argument misrepresents dialogical egalitarianism, which states that the requirement to support (or else retract) a dialogical commitment is conditional upon that commitment's being challenged by another dialogue party, rather than unconditional as the argument suggests and requires. The alleged regress of supporting propositions would thus only ensue if one was faced with a persistent interlocutor (Rescorla 2009b: 54-56). Yet, third, such a regress of supporting propositions cannot lead to global scepticism, due to the separation of dialogical from attitudinal commitments established above. Even if I find myself unable to establish $\mathrm{P}$ to a persistent interlocutor, this does not imply that I take an agnostic attitude towards $\mathrm{P}$, attitudinally committing to neither $\mathrm{P}$ nor $\neg \mathrm{P}$. It may be held to imply that I ought to commit in attitude to neither $\mathrm{P}$ nor $\neg \mathrm{P}$, due to some prescription to the effect that one's inability to establish $\mathrm{P}$ to someone else renders it impermissible to believe $\mathrm{P}$ oneself. But it is far from obvious why dialogical egalitarians (or anyone else, for that matter) should accept such a prescription. Dialogical egalitarianism consequently does not imply global scepticism.

A parallel, exclusively dialogical argument holds that dialogical egalitarianism leaves us unable to establish the truth of any proposition in dialogue if faced with a persistent interlocutor. In that event one cannot escape the ensuing dialogical regress in any way other than by abandoning the attempt to establish the given

\footnotetext{
${ }_{9}^{9}$ Independent grounds for the effective impermissibility of begging the question are provided in Sect. 5.
} 
proposition to one's interlocutor. This argument, however, fails by begging the question, since dialogical egalitarians regard the inability to establish a proposition to a persistent interlocutor as unproblematic. Few interlocutors are actually persistent in their challenges, and those few merely demonstrate 'the unfortunate fact that there is simply no reasoning with some people' (Rescorla 2009b: 47). For dialogical foundationalists it is unacceptable that one's attempt to establish to an interlocutor the truth of any proposition at all may falter at the whim and mercy of that interlocutor. Yet dialogical foundationalists cannot invoke this unacceptability in an argument against dialogical egalitarianism, on pain of begging the question. We can thus conclude that arguments against dialogical egalitarianism from the threat of scepticism and from a parallel, exclusively dialogical threat fail as well.

The last argument against dialogical egalitarianism invokes propositions ostensibly so basic that they should be accepted by default when asserted, placing the burden of proof on anyone attempting to detract from dialogical commitment to their truth. Eight types of such putatively privileged propositions have been distinguished (Rescorla 2009a: 89; cf. Moyal-Sharrock 2005: 102-103). These include (with examples in parenthesis): introspective reports (I feel happy); perceptual reports (I see a ship ${ }^{10}$ ); autobiographical reports (I have never been to Tasmania); reports of one's immediate environment (The armchair in front of me is burning); reports of knowledge that is basic within one's specifically located community (The Earth is flat); reports of knowledge that is basic in all communities (The sky is blue by day); basic conceptual truths (All kangaroos are animals); basic logical and mathematical truths $(1-1=0)$. According to the present argument, asserted propositions of any of these types must obviously be privileged, as it would seem confused, misguided, deviant, or in some other way inappropriate for one's interlocutor to demand support for the asserted proposition. Equally, then, it would seem counter-intuitive to accept a thesis that permits such preposterous questioning. Hence dialogical egalitarianism should be rejected (Rescorla 2009a).

Again, however, this argument begs the question against dialogical egalitarians, who reject the putative privilege of these propositions. The charge that dialogical egalitarians fail to recognise the inappropriateness of questioning these propositions absent sufficient support for their negations is plainly circular, as they deny that very inappropriateness. It remains circular even with regard to what may be considered the most obviously foundational propositions, viz. basic conceptual, logical and mathematical truths. Take the mathematical truth that $1-1=0$. Dialogical egalitarians would deny the impermissibility of questioning its assertion, and would consequently accept the burden of supporting it if needed. To support it, they might cast $1-1=0$ as the symbolisation in Arabic numerals of the proposition that One, less one, is none. And of course, that proposition might in turn be questioned. Since dialogical egalitarians do not regard it as problematic that such putatively foundational propositions as $1-1=0$ can be questioned in the absence of

\footnotetext{
10 The truth of such putatively privileged propositions is irrelevant here, as is, therefore, the possibility that I am not seeing a ship but rather a crashed UFO cleverly disguised as a ship by the Fake Barn County Intelligence Agency.
} 
sufficient support for their negations, alleging that it is problematic simply begs the question against dialogical egalitarianism.

Indeed, dialogical egalitarians can turn the argument on its head, by charging its foundationalist proponents with sheer dogmatic insistence on propositions of the foregoing eight types (or else on their privileged status; Rescorla 2009b: 46, 51). Thus reversed, however, the argument does not carry any force without the assumption that dogmatism is impermissible. Yet dogmatism about (the privileged status of) the aforelisted propositions, rather than being deemed impermissible, is exactly what is stipulated by dialogical foundationalism-so the reversed argument would equally be question-begging. Whether directed against dialogical egalitarianism or dialogical foundationalism, the argument offers no support for either thesis.

The predominance of arguments against dialogical egalitarianism may suggest that dialogical egalitarianism is assumed to hold by default, while dialogical foundationalism would need to be established against it. Beyond the appeal to the impermissibility of dogmatism that has just been rejected, this apparent default status of dialogical egalitarianism may be due to an appeal to the cognitive value of simplicity, as arguably instantiated to a higher degree by dialogical egalitarianism. Yet such an appeal would again be question-begging, as dialogical foundationalists may simply attach more weight to the cognitive value of conservatism (which ostensibly favours dialogical foundationalism). Moreover, any unsupported claim in the face of challenges that dialogical egalitarianism should be accepted by default would be patently self-undermining. We are thus left without any successful argument in favour of either dialogical egalitarianism or dialogical foundationalism.

Nevertheless, a resolution of the debate is required if we wish to avoid perennially returning to this debate when discussing more substantive issues. Yet absent a successful argument for either thesis, we can only resort to deliberating about which of the two theses it is more instrumentally rational, that is, prudent, to accept, employ and presume in our philosophical dialogues. In place of principled arguments with unrestricted scope of application, we must turn to pragmatic considerations about philosophical dialogue, thereby restricting the scope of application of any subsequent conclusion about the competing theses to analytic philosophy only. Yet in order to determine which thesis it is more instrumentally rational to adopt in analytic philosophy, we must first determine the goal(s) to the attainment of which the thesis would be so instrumental. That is, we must first identify the goal or goals of analytic philosophical dialogue. To this end I present a quantitative content analysis of contributions to philosophical dialogues in the next two sections, based on Douglas Walton's typology of dialogues. The result of this analysis strongly suggests that it is the prevalent goal of analytic philosophical dialogues to persuade one's opponent. In light of this goal, I argue in Sect. 6 that dialogical egalitarianism is more conducive to that goal's attainment and should thus prudently be adopted in analytic philosophy. 


\section{Types of Dialogue}

Douglas Walton and colleagues have distinguished seven practically mutually exclusive but not necessarily exhaustive ideal types of dialogue, abstracted from real-life dialogues imperfectly instantiating one or more ideal types (Walton 2014: 33). The ideal types, catalogued with key characteristics in Table $1,{ }^{11}$ are distinguished according to both the goals pursued in a given type of dialogue and the assumed rules of engagement accompanying these goals (Walton and Krabbe 1995: 66). The relative significance of different goals, however, appears to diverge between adversarial and collaborative types of dialogue. An adversarial type of dialogue can be delineated essentially by the goal of each individual participant, while what Walton calls the goal of the dialogue overall is a side benefit not necessarily pursued by participants. By contrast, in a collaborative type of dialogue the overall goal of the dialogue is essential to the dialogue and is shared by each participant, while participants' individual goals (aside from this shared goal) merely contribute to the pursuit of the shared goal.

Before this typology can be employed for the analysis of philosophical dialogues, several further characteristics must be noted (see Walton 2014: 34-36, 42, 236-238). Both inquiry dialogues and discovery dialogues aim at the production of evidentially supported knowledge. However, an inquiry dialogue aims to conclusively establish whether it is the case that $\mathrm{P}$ (or otherwise to show that this cannot currently be established), whereas a discovery dialogue aims to explain why it is the case that P. Consequently, a hypothesis to be tested is already given in an inquiry dialogue, while one or more hypotheses must first be formulated in a discovery dialogue before these are tested (McBurney and Parsons 2001: 417-418). Once identified, however, it is characteristic of both inquiry and discovery dialogues that a hypothesis is submitted to testing in order to gather supporting or detracting evidence. At the same time, the standard of evidential support to be satisfied in order to successfully conclude an inquiry dialogue is much higher than the corresponding standard in a discovery dialogue, since achieving the goal of the former but not of the latter requires that subsequent retraction of its conclusion is precluded.

In contrast to dialogues of these two types, deliberation dialogues and negotiation dialogues are not aimed at acquiring knowledge but instead at the consensual coordination of subsequent action. Between themselves they differ centrally in the compatibility of participants' preferences: Participants engage in deliberation dialogue with each other if their individual preferences are jointly realisable, and in negotiation dialogue if they are not. Furthermore, achieving a deliberated consensus that actually satisfies each participant's preferences requires the full disclosure of any such preferences, whereas maximising one's preference satisfaction as part of a negotiated consensus requires the strategic and likely limited disclosure of one's preferences.

In any persuasion dialogue either one or each party to the dialogue attempts to get her opponent to abandon his initial dialogical truth-value commitment regarding

\footnotetext{
11 Where necessary I have adapted the description of characteristics to take account of the separation between attitudinal and dialogical commitments.
} 
Table 1 Types of dialogue. Adapted from Walton and Krabbe (1995: 66), Walton (2013: 200-202), Walton (2014: 34). Essential goals are italicised

\begin{tabular}{|c|c|c|c|c|}
\hline $\begin{array}{l}\text { Type of } \\
\text { dialogue }\end{array}$ & Initial situation & $\begin{array}{l}\text { Relation of } \\
\text { participants }\end{array}$ & $\begin{array}{l}\text { Goal of any } \\
\text { participant }\end{array}$ & Goal of the dialogue \\
\hline $\begin{array}{l}\text { Information- } \\
\text { seeking }\end{array}$ & Need for information & Collaborative & $\begin{array}{l}\text { Acquire or give } \\
\text { information }\end{array}$ & Exchange information \\
\hline Inquiry & $\begin{array}{l}\text { Need for conclusive } \\
\text { proof or disproof of } \\
\text { a hypothesis }\end{array}$ & Collaborative & $\begin{array}{l}\text { Find and verify } \\
\text { evidence }\end{array}$ & $\begin{array}{l}\text { Prove or disprove } \\
\text { hypothesis }\end{array}$ \\
\hline Discovery & $\begin{array}{c}\text { Need for explanation } \\
\text { of a phenomenon }\end{array}$ & Collaborative & $\begin{array}{l}\text { Find and assess } \\
\text { potential } \\
\text { explanation }\end{array}$ & $\begin{array}{l}\text { Choose best } \\
\text { explanation for } \\
\text { phenomenon }\end{array}$ \\
\hline Persuasion & $\begin{array}{l}\text { Conflict of dialogical } \\
\text { commitments }\end{array}$ & Adversarial & $\begin{array}{l}\text { Get opponent to } \\
\text { adopt your } \\
\text { dialogical } \\
\text { commitment }\end{array}$ & $\begin{array}{l}\text { Resolve or clarify } \\
\text { conflict of } \\
\text { commitments }\end{array}$ \\
\hline Deliberation & Need for action & Collaborative & $\begin{array}{l}\text { Coordinate goals } \\
\text { and actions }\end{array}$ & $\begin{array}{l}\text { Agree a course of } \\
\text { action for } \\
\text { implementation }\end{array}$ \\
\hline Negotiation & $\begin{array}{l}\text { Conflict of interests } \\
\text { and expected benefit } \\
\text { of agreement }\end{array}$ & $\begin{array}{l}\text { Adversarial } \\
\text { and } \\
\text { collaborative }\end{array}$ & $\begin{array}{l}\text { Maximise your own } \\
\text { benefit }\end{array}$ & $\begin{array}{l}\text { Reach a mutually } \\
\text { acceptable settlemen }\end{array}$ \\
\hline Eristic & Personal conflict & Adversarial & $\begin{array}{l}\text { Verbally hit out at } \\
\text { opponent }\end{array}$ & $\begin{array}{l}\text { Reveal deeper basis of } \\
\text { conflict }\end{array}$ \\
\hline
\end{tabular}

some proposition $\mathrm{P}$ in favour of her own commitment (cf. Walton 1992: 137). ${ }^{12}$ Such a change of commitment is pursued in this ideal type by presenting a chain of arguments culminating in one's initial commitment regarding $\mathrm{P}$, based only on commitments made or assumed to be made by one's opponent. The goal of persuasion dialogue is commonly considered to be a change in the opponent's attitudinal rather than dialogical truth-value commitment. Pursuit of an attitudinal change, however, practically requires pursuit of a dialogical change: Any pursuit of an attitudinal change in one's interlocutor requires some speech act to the potential effect of that attitudinal change; and such a speech act equally has the potential to effect a dialogical change. ${ }^{13}$ The immediate and indispensable goal of persuasion dialogue, then, is simply to lead one's opponent to adopt one's own dialogical commitment, though one's mediate goal may of course still be a change in one's opponent's attitudinal commitment. (The label of persuasion for this type of

\footnotetext{
${ }^{12}$ Given one's initial commitment to $\mathrm{P}$, one's opponent may either dissent from $\mathrm{P}$, by committing to neither $\mathrm{P}$ nor $\neg \mathrm{P}$, or he may dispute that $\mathrm{P}$, by committing to $\neg \mathrm{P}$ (and attempting to get one to commit to $\neg \mathrm{P}$ as well). Any persuasion dialogue features one or the other initial situation (cf. van Eemeren and Grootendorst 1983: 82).

13 This distinction is not to be confused with Michael Dummett's (1978: 295-296) distinction between suasive and explanatory arguments. An explanatory argument would be made, as Dummett states, when one's interlocutor has already committed to the truth of its conclusion; yet the aim of persuasion dialogue is to bring about such commitment in the first place.
} 
dialogue is therefore slightly misleading, though I retain it for the sake of consistency with the literature.)

Persuasion dialogue can thus be located between the foregoing two pairs of types of dialogue. Consistent with inquiry and discovery dialogue, the object of the conclusion of a persuasion dialogue is a proposition rather than a set of actions. (Note that a persuasion dialogue is not itself action-guiding: Even when the proposition at issue concerns what ought to be done, the dialogue differs from a deliberation or negotiation dialogue, as the latter concern what will be done.) Further, in line with deliberation and negotiation dialogue, the successful conclusion of a persuasion dialogue requires consensus rather than evidentially supported knowledge (though knowledge may of course contribute to reaching consensus). As such it is neither necessarily nor typically part of a persuasion dialogue to submit a hypothesis to tests in order to gather supporting or detracting evidence. Moreover, consistent with inquiry dialogue, the proposition at issue in a persuasion dialogue is given from the start. In line with discovery dialogue, achieving the essential goal of a persuasion dialogue does not necessitate a particularly high standard of support and so does not preclude retraction.

In identifying the type of a given dialogue, lastly, it is imperative to not be misled by either embedded dialogues or interlocutors' self-conceptions. The pursuit of the essential goal of a dialogue of one type may require a temporary shift to a separate dialogue of a different type that is embedded within the original dialogue for the purpose of advancing the latter (Walton 2014: 37). Embedded within a (long) deliberation dialogue, for instance, may be several persuasion dialogues and information-seeking dialogues (Walton 2014: 212, 217). Crucially, the type of an embedded dialogue has no bearing on the type of the dialogue wherein it is embedded, nor vice versa. Similarly, and mirroring the separation between attitudinal and dialogical commitments, the self-conception of interlocutors regarding the type of their dialogue need not correspond to the actual type of the dialogue. Participants may, for instance, believe to be engaged in an inquiry dialogue while the dialogue actually qualifies as a persuasion dialogue according to the aforelisted characteristics (cf. Walton 1992). In determining the types of philosophical dialogues we should thus rely neither on the types of embedded dialogues nor on the types supposed by participants. Rather, we will need to draw only on the listed characteristics.

\section{Analysis of Dialogues in Philosophy}

I will now apply this typology in a quantitative content analysis, in order to determine the relative prevalence in current philosophy of these types, thus to identify the prevalent goal or goals of philosophical dialogue. It may initially appear difficult to do so, as philosophical dialogues are located variously in informal conversation, or in formal debate, or between imagined dramatis personae, or in successive publications, with one contributor taking over from another, through minutes, months, years, or even centuries' (Cohen 1986: 3). Conveniently, however, articles in peer-reviewed journals are very often developed out of (actual or 
hypothetical) oral dialogues, and are the predecessors of the further elaboration of their contents in monographs. As such, journal articles are contributions to ongoing dialogues (between parties whose membership is ever-changing) that are conducted near-exclusively through journal articles, oral dialogues, and monographs, the latter two feeding into or drawing upon journal articles. So an analysis of the prevalence of different types of dialogue across a representative sample of journal articles will also be representative of the types of dialogue of these ongoing dialogues, thus offering a sufficiently broad and inclusive snapshot of contemporary philosophical dialogues.

It may further appear that journal articles themselves constitute monologues rather than dialogues, rendering the analysis of individual articles uninformative with regard to the relative prevalence of different types of dialogue in philosophy. However, between its conception and its publication a journal article undergoes a process of development and refinement through (actual or hypothetical) oral or written dialogue and, ultimately, peer-review. Thereby, in order to pass (the next round of) peer-review and editorial selection, objections and improvements by parties other than the authors' are integrated into and addressed in the article, in effect internalising the contributions of such other parties into the article (Dutilh Novaes 2016). A philosophical journal article thus reflects a sustained dialogue between the authors and other parties, which is itself both part of and a contribution to a longer, ongoing dialogue.

In sampling journal articles for analysis, it is desirable to guard against claims that the selected articles do not represent adequately what is considered best philosophical practice. To that end I select articles for analysis exclusively from those 22 journals that are listed among the top- 25 in both of the leading reputational journal rankings (Brooks 2011; Leiter 2013). ${ }^{14}$ For a minimally sufficient sample of current work in philosophy, I analyse five articles from each of these 22 journalsone each published in every even-numbered year between 2006 and 2014. In selecting these 110 articles I furthermore disregard articles published within special issues and symposia, for the sake of consistency within the sample, just as I disregard discussion notes, reviews, editorial material and obviously satirical articles. ${ }^{15}$ Among the articles thus remaining, I select, arbitrarily, the third article published in the given journal in the given year's volume(s). Note that none of the articles thereby selected turned out to be in so-called continental philosophy, and all were written in English. The sample thus exclusively represents current so-called analytic Anglophone philosophy, though it should be expected in light of shared

\footnotetext{
14 These 22 journals include: American Philosophical Quarterly, Analysis, Australasian Journal of Philosophy, British Journal for the Philosophy of Science, Canadian Journal of Philosophy, Erkenntnis, Ethics, European Journal of Philosophy, Journal of Philosophy, Journal of the History of Philosophy, Mind, Noûs, Pacific Philosophical Quarterly, Philosophers' Imprint, Philosophical Quarterly, Philosophical Review, Philosophical Studies, Philosophy and Phenomenological Research, Philosophy and Public Affairs, Philosophy of Science, Proceedings of the Aristotelian Society, Synthese. Given their reputational ranks, these journals are relatively most likely to publish work instantiating what is predominantly regarded as best philosophical practice. Of course, this implies that they publish work actually instantiating best philosophical practice only insofar as 'best philosophical practice' is defined by a professional mainstream.

15 The only satirical article thus disregarded is Willoughby (2012), which I will return to shortly.
} 
methods and topics that it is also representative of non-Anglophone analytic philosophy.

Analysing the sampled articles, I identify the exemplified type of dialogue in two steps. First the non-embedded dialogue in the article must be distinguished from any dialogues embedded within it. Many articles, for instance, provide initial definitions and/or an overview of the state of the debate on an issue. This provision of background information (itself seemingly instantiating information-seeking dialogue) serves to facilitate the dialogues that follow it, and is thus embedded within one of these subsequent dialogues. Equally, an article may incorporate an inquiry dialogue wherein a given hypothesis is being tested, with the test result being employed to advance some other dialogue in the article and the inquiry thus being embedded within that other dialogue. As such, the task in this step is, first, to assess each paragraph or similar unit of text in an article for its function or purpose within the article as a whole. Second, it is necessary to identify the passages or paragraphs that together serve the same function or purpose, thus identifying the different dialogues in the article (such as a series of paragraphs that provide background information on existing arguments, followed by several paragraphs attempting to undermine those arguments). Third, from among the dialogues thus distinguished it is necessary to identify the dialogue that is facilitated or advanced by all others without itself facilitating or advancing any other dialogue. On the basis of the functions of the various paragraphs of an article I thus identify the one dialogue (i.e. series of passages or paragraphs) in which all other dialogues are embedded. (No article contains a plurality of such non-embedded dialogues; for if it did, it would be pursuing a plurality of separate and wholly independent conclusions or purposespresumably barring it from publication at least in any of the above 22 journals.)

The next task is to identify the type of the non-embedded dialogue. Here I assess every non-embedded dialogue against the characteristics of each type listed above. These characteristics are themselves qualitative rather than quantitative, so the assessment of their respective instantiation or non-instantiation is inevitably interpretive. To mitigate against undue bias, I disregard any characteristics in the analysis of a given non-embedded dialogue whose instantiation is not unambiguous and readily apparent, thus basing the analysis of a given non-embedded dialogue solely upon those characteristics whose instantiation is clear and unequivocal (which turned out to be true of most cases). On this basis I judge the type of a given non-embedded dialogue according to the preponderance of evidence from the individual characteristics, though for most dialogues the type was so clear as to leave very little scope for reasonable doubt, where the assessed characteristics effectively admitted of the identification of only one type. ${ }^{16}$ In order to uncover any significant level of error in this analysis I furthermore repeated the analysis for $20 \%$ of the sample (viz. one article selected at random from each of the 22 journals). This led to no corrections of the initial result.

\footnotetext{
16 I suspect that the very high standards of writing applied to publications in top-ranked philosophy journals provide at least part of an explanation for this relative clarity of the types of dialogue of sampled articles.
} 
I will now illustrate this analysis using the example of Willoughby (2012) - a satirical article published in the Journal of Philosophy. This article satirises certain aspects of philosophical dialogue, so its type of dialogue is potentially indicative of the type that is prevalent among the satirised philosophical dialogues. Authored under the pseudonym of New York City subway stop Myrtle Willoughby and entitled 'Stoppism: Retrospects and Prospects', Willoughby (2012) offers an attack on stoppism: the thesis that trains are metaphysically dependent upon stops, such that a train is a local (or express) train because it calls at local (or express) stops. That thesis is contrasted in the introductory section of the article from theses affirming dependence in the reverse direction (train-realism), no dependence at all (coincidentalism), dependence of both trains and stops upon some other thing 'inside the subway' (naturalism) and dependence of both upon some other thing 'outside the subway' (theological views; 2012: 282). With stops understood roughly as the places where one boards or alights a train, the author outlines fictional historical debates regarding stoppism in Sect. 1, discussing such problems as the obvious fact of trains sometimes being motionless between stops. This fact seemed inexplicable under stoppism prior to the invention of precise instruments for timekeeping that enabled us to recognise a train's stop between stops as caused by some other train's stop at a stop (thus reviving stoppism). In Sect. 2 the author discusses four generally known facts that are difficult for stoppists to accommodate, including, for instance, that stops change under certain conditions from being local to being express stops or vice versa, which is inexplicable if stops are metaphysically basic. The author here also considers the naturalistic thesis of station-stoppism, which regards stations as metaphysically basic entities possessing varying, numerous and fine-grained stop-properties (that are themselves left for scientists to investigate). This thesis is rejected, as it would leave us unable to specify the identity conditions of any single station. Other naturalistic deflations of stoppism are discussed in Sect. 3, all being rejected due to failure to provide 'a set of natural facts [consistent with stoppism] on which to rest the local-stop/expressstop distinction' (2012: 293). In the concluding Sect. 4 the author thus rejects stoppism.

Turning to the analysis of this satirical article, it should initially be noted that satire depicts as laughable a target that is taken seriously by certain people, thus effectively depicting as laughable the people taking said target seriously. Depicting an interlocutor as laughable may be regarded as a contribution to an eristic dialogue. But for present purposes this satire is more instructive if we identify its type of dialogue on the counterfactual assumption that the article is serious rather than satirical. Given that assumption, we must first distinguish the different dialogues within the article, in order to identify the non-embedded dialogue. The introductory section and Sect. 1 together provide a basic overview of the logical space and fictional historical development of stoppism, seemingly for the purpose of ensuring that readers possess certain background information. In contrast, Sects. 2 and 3 set out various considerations against stoppism (which are distilled in Sect. 4), with the clear purpose of undermining stoppism. Thus there are two dialogues in this article, distinguished by their respective goals. If one dialogue furthers the other one (and not vice versa), then that dialogue is embedded within the other dialogue. And this 
is clearly the case: The dialogue in the earlier sections advances the dialogue thereafter by preparing the ground for the latter. So we need not be concerned further with the earlier dialogue (which appears to be an information-seeking dialogue) and can focus upon the later sections.

The object of the conclusion pursued in that non-embedded dialogue is a proposition (viz. the thesis that stoppism is false) rather than a set of actions, so this dialogue instantiates inquiry, discovery, or persuasion dialogue, thus having the goal of (dis)proving some hypothesis, choosing the best explanation for some phenomenon, or getting the author's opponent to adopt the author's dialogical commitment. We can rule out discovery dialogue, both because there is no single, overarching phenomenon at issue here that would demand explanation, and because the proposition at issue is given from the start. But the essential goals, though perhaps suggestive, are not obviously decisive between inquiry and persuasion dialogue: Is it the goal of this dialogue to disprove stoppism or to get the author's opponent to reject stoppism? We need to assess the dialogue against the other characteristics of inquiry and persuasion dialogue to answer this question. The initial situation of the dialogue does not appear to exemplify a need for conclusive proof of a hypothesis, which speaks against this article's characterisation as instantiating inquiry dialogue. Moreover, the relation between participants is clearly adversarial rather than collaborative, further suggesting that the article instantiates persuasion dialogue. Additionally, the characterisation of persuasion dialogue as offering a chain of arguments seems to match exactly the non-embedded dialogue of this article. Overall, then, we can conclude that the non-embedded dialogue of this satirical article instantiates persuasion dialogue.

Does the type of dialogue of this satire, then, prove to be indicative of the prevalent type of dialogue among the sampled articles analysed here? It does indeed, as the results in Table 2 show. Of the non-embedded dialogues of the 110 sampled articles, $95.5 \%$ are found to instantiate persuasion dialogue. ${ }^{17}$ This result strongly suggests that the vast majority of philosophical dialogues represented here are essentially characterised by the goal of each participant with an initial dialogical truth-value commitment regarding a given proposition $\mathrm{P}$ to influence her opponent by way of argument to the effect that the opponent abandons his initial dialogical truth-value commitment regarding $\mathrm{P}$ and instead adopts her initial dialogical truthvalue commitment regarding $\mathrm{P}^{18}$ In effect, the essential dialogical goal of the vast majority of dialogues in current analytic philosophy is to succeed against one's opponent in argument. ${ }^{19}$

\footnotetext{
17 Perhaps notably, every article not instantiating persuasion dialogue was in the philosophy of science or (in one case) in metaphilosophy. Even so, the sample included 26 articles that fall into one or another field within the philosophy of science, of which 22 articles instantiated persuasion dialogue.

18 Begging the question is thus prudently impermissible, as it undermines the prospects of persuading a philosophical opponent. Cf. fn.9.

19 One might claim that the fundamental but attitudinal goal of philosophy is to acquire knowledge, thus attitudinally pursuing the goal of inquiry or discovery dialogue, by interrogating hypotheses in persuasion dialogue. Such a claim, however, would be very uncharitable, ascribing to philosophers both the immodesty of holding that their own inability to defeat a hypothesis of itself constitutes evidence of the truth of that hypothesis, and more importantly the imprudence of acting accordingly, by pursuing an
} 
Table 2 Frequency of types of dialogue

\begin{tabular}{lcc}
\hline Type of dialogue & Non-embedded dialogues of journal articles instantiating the type of dialogue \\
\hline Information-seeking & 0 \\
Inquiry & 3 \\
Discovery & 0 \\
Persuasion & 105 \\
Deliberation & 2 \\
Negotiation & 0 & 0 \\
Eristic & 0
\end{tabular}

\section{The Prudence of Dialogical Egalitarianism in Philosophy}

I have argued earlier that none of the existing arguments for dialogical foundationalism or dialogical egalitarianism succeed. Hence the only available resolution of the debate between these two theses is to adopt whichever thesis it is more prudent, or instrumentally rational, to act upon in one's dialogical engagements in philosophy. In order to determine which thesis it is more prudent to adopt in our philosophical dialogues, we first needed to identify the goal of such dialogues, which is (in nearly all analytic philosophical dialogues) the persuasion of one's opponent, that is, the influencing of one's opponent to the effect that he adopts one's own initial commitment regarding a given proposition. We must thus ask whether the adoption in analytic philosophical dialogues of either dialogical egalitarianism or dialogical foundationalism is more conducive to the persuasion of one's opponent.

The answer, of course, is easily found. Egalitarianism and foundationalism differ with regard to the putatively privileged status of certain ostensibly foundational propositions. Take, then, any such putatively privileged proposition P. Imagine you dialogically commit to $\mathrm{P}$, and your interlocutor questions whether $\mathrm{P}$ (committing dialogically to neither $\mathrm{P}$ nor $\neg \mathrm{P}$ ) without presenting any support for $\neg \mathrm{P}$. Which reaction on your part is more likely to lead to your interlocutor's also dialogically committing to $\mathrm{P}$ ? That is, which reaction on your part is less likely to be detrimental to your attempt to persuade your opponent (as well as other members of your opponent's party to the ongoing dialogue) that P? Is it, either, your insisting that she should not question whether $\mathrm{P}$ without sufficiently supporting $\neg \mathrm{P}$; that she should simply accept that $\mathrm{P}$ absent such support; and that she should only expect you to offer support for $\mathrm{P}$ after she has provided sufficient support for $\neg \mathrm{P}$ ? Or is it, alternatively, your offering support for $\mathrm{P}$ ? The prudence of the latter reaction is obvious: Insisting on the privileged status of $\mathrm{P}$, as in the former reaction, is useless (or positively counter-productive) as a means of persuading the members of the opposing party who have already questioned whether $\mathrm{P}$. That is, insisting on the

Footnote 19 continued

attitudinal goal associated with one type through dialogue optimised for the pursuit of the goal of another type. 
putative privilege of $\mathrm{P}$ is simply ineffective for the purpose of succeeding against one's opponent in philosophical dialogue. Such privilege is, therefore, practically non-existent, whereupon dialogical foundationalism collapses, for practical purposes, into dialogical egalitarianism in philosophical persuasion dialogue. Pragmatically, then, the adoption of dialogical egalitarianism in analytic philosophical persuasion dialogues is inescapable.

Of course this result applies to analytic philosophical dialogues that have been found to instantiate persuasion dialogue, and it does not apply to such dialogues as have been found to instantiate a type other than persuasion dialogue. Yet where the type of the dialogue one is currently engaged in has not yet been identified, it is exceedingly likely (given the foregoing empirical results) that this dialogue too instantiates persuasion dialogue. That likelihood renders it prudent to adopt dialogical egalitarianism in any analytic philosophical dialogue that has not been identified as instantiating a type other than persuasion dialogue. Given the practical difficulty of analysing the type of one's own, ongoing dialogue with another party, this effectively applies to all analytic philosophical dialogues. In practice, then, dialogical egalitarianism must prudently be adopted in all analytic philosophical dialogues. If one has committed to $\mathrm{P}$ in such a dialogue, and if $\mathrm{P}$ is subsequently questioned by another party, then the burden of proof thus imposed prudently cannot be evaded. Instead, one's commitment to $\mathrm{P}$ must prudently be supported. The putative privilege of $\mathrm{P}$ has no bearing on this prudential distribution of the burden of proof.

Perhaps the most significant implication of this result for analytic philosophy is the prudential rejection of any privileged status of propositions that affirm the evidential value of common sense, intuitions, thought experiments or other a priori sources of evidence. Pace Chisholm, Bealer and Williamson, dialogical commitments to such propositions are not privileged and, having recently faced ample questioning, must prudently be supported. Failing that, commitments to such propositions would prudently have to be retracted, whereupon these a priori sources of evidence would have to be excised from philosophical dialogue. (Their employment in merely attitudinal musings is of course unaffected by such excision, as dialogical egalitarianism does not imply any attitudinal prescriptions. ${ }^{20}$ ) In the attempt to salvage the apparently widespread employment of such a priori sources of evidence in substantive analytic philosophical debates it is thus imperative to provide (ideally conclusive) support for their alleged evidential value.

\footnotetext{
${ }^{20}$ Cf. Sect. 3 above. This notably suggests a defence from the charge of scepticism for Robert Cummins's (1998) calibration argument: If the requirement for the calibration of intuitions was interpreted exclusively dialogically, then no attitudinal and thus no epistemological implications arise from it.
} 


\section{Two Objections}

Two potential objections must still be addressed. These include claims that my foregoing quantitative research is not representative of analytic philosophical dialogues, and that my considerations are self-undermining. I briefly discuss these objections in turn.

The analysed sample of philosophical work, though representative of articles recently published in regular issues of highly reputed Anglophone philosophical journals, may nevertheless be argued to fail to be representative of current Anglophone (and other) analytic philosophical dialogues. It is perhaps easier, in various ways, to have an article-length philosophical work published in less highly reputed journals, in special issues, or in edited books. This difference may encourage philosophers to submit different kinds of work (more exegetical work, say) to such venues, potentially leading to a different distribution of types of dialogue in these venues relative to the distribution observed in regular issues of highly reputed journals. I grant that it would indeed be desirable to extend the present quantitative research to these venues in the future. Yet cursory examination of work published there already suggests that persuasion dialogue is at least similarly prevalent in such work. In the analysed sample, moreover, the probability of choosing, at random, an article not instantiating persuasion dialogue is below .05; hence even a somewhat higher probability in these other venues would not suffice to undermine the prudence of adopting dialogical egalitarianism in our philosophical dialogues.

Given dialogical egalitarianism, however, even the presumptions that underlie the considerations raised here may be questioned, including in particular the deductive and other inferential rules that I relied upon. In the event that all inference rules are indeed questioned, any argument in defence of such questioned rules would seem unavailable, since an argument must itself employ such a rule in order to infer a conclusion from a given set of premises. Nor would claims to the privileged status of these inference rules be available, because such claims would seemingly contravene the dialogical egalitarianism advocated in this paper. Hence a challenge to all rules of inference, it seems, could neither be answered nor could it be deflected here, thus apparently undermining the foregoing considerations in favour of dialogical egalitarianism on the basis of these same considerations. Of course, such a challenge would equally undermine any argument for dialogical foundationalism in philosophical persuasion dialogues.

Aside of that, however, this challenge would also misconstrue the nature and conclusion of the considerations offered in this paper. These considerations have been premised explicitly on the overarching dialogical goal of persuading one's opponent, so they do not apply to dialogues that follow a different overall goal, such as persuasion dialogues embedded within a dialogue of a different type. That is to say, my present considerations are applicable only to non-embedded persuasion dialogues in philosophy. Yet no such non-embedded persuasion dialogue is to be found in this paper. The overarching dialogical goal of my considerations is not one of persuasion but rather of deliberation: My considerations offer advice on how best 
(or most prudently) to attain a given goal. They do not consider the normative or evaluative status of that or any other goal, nor of any course of action adopted in pursuit of the given goal. Rather, they merely seek to aid in deciding upon the most effective or instrumentally rational course of action that will be taken in pursuit of this given goal. As such, my present considerations quite clearly instantiate deliberation dialogue. Though Sects. 3 and 6 above (aside of their respective opening and closing paragraphs) are plausibly characterised as contributions to a persuasion dialogue, these contributions are themselves embedded within the overarching deliberation dialogue of this paper. Now, since my considerations recommend dialogical egalitarianism for non-embedded philosophical persuasion dialogues, they do not apply to the non-embedded deliberation dialogue of this paper, and hence do not here require me to adopt dialogical egalitarianism. ${ }^{21}$ Consequently, my foregoing considerations are not rendered self-undermining by a challenge to all rules of inference.

Acknowledgements This paper arose from very fruitful discussions with Sonja Erikäinen, for whose inspiration and continued advice I am most grateful. I equally thank Keith Allen, Ruby Chan, Emmanuela Kritikaki and Mary Leng for much useful feedback that has helped shape the considerations presented here. Different parts of this paper have further benefited from comments by Michael Beaney, Alexander Bird, Christopher Jay, Finn Spicer, Alessandra Tanesini, Sara Uckelman, Douglas Walton, Dagmar Wilhelm, and an anonymous reviewer for this journal, as well as by audience members at the Universities of Bochum, Bristol, Glasgow, Granada, Leeds, and York. I am especially indebted to Ruby Chan, Sonja Erikäinen, Emmanuela Kritikaki, Nicola McCallum, Lubna Nowak, and Naomi Philips.

Open Access This article is distributed under the terms of the Creative Commons Attribution 4.0 International License (http://creativecommons.org/licenses/by/4.0/), which permits unrestricted use, distribution, and reproduction in any medium, provided you give appropriate credit to the original author(s) and the source, provide a link to the Creative Commons license, and indicate if changes were made.

\section{References}

Aijaz, Imran, Jonathan McKeown-Green, and Aness Webster. 2013. Burdens of proof and the case for unevenness. Argumentation 27: 259-282.

Bealer, George. 1996. On the possibility of philosophical knowledge. Philosophical Perspectives 10: $1-34$.

Brooks, Thom. 2011. In your judgment, which of the following is the better philosophy journal? All Our Ideas. http://www.allourideas.org/philosophyjournals/results?all=true. Accessed 17 June 2015.

Chisholm, Roderick M. 1976. Person and object: A metaphysical study. La Salle: Open Court.

Cohen, L. Jonathan. 1986. The dialogue of reason: An analysis of analytical philosophy. Oxford: Clarendon Press.

Cummins, Robert. 1998. Reflections on reflective equilibrium. In Rethinking intuition: The psychology of intuition and its role in philosophical inquiry, ed. Michael R. DePaul, and William Ramsey, 113-127. Lanham: Rowman and Littlefield.

\footnotetext{
21 This is not to say that it would be prudent or otherwise appropriate to adopt dialogical foundationalism in non-embedded philosophical deliberation dialogue. Though it is of no present import, neither dialogical egalitarianism nor dialogical foundationalism appear to be appropriate in deliberation dialogue, as there does not seem to exist any burden of proof in such dialogue (cf. Walton 2014: 232-6).
} 
Dummett, M. 1978. The justification of deduction. In Truth and other enigmas, 290-318. Cambridge: Harvard University Press.

Dutilh Novaes, Catarina. 2016. Reductio ad absurdum from a dialogical perspective. Philosophical Studies 173 (10): 2605-2628.

Dyke, Heather. 2013. On methodology in the metaphysics of time. In The future of the philosophy of time, ed. Adrian Bardon, 169-187. New York: Routledge.

Kuhn, Thomas S. 1962. The structure of scientific revolutions. Chicago: University of Chicago Press.

Leiter, Brian. 2013. Poll results: Which are the "best" (highest quality) philosophy journals (regardless of area)? Condorcet Internet Voting Service. http://www.cs.cornell.edu/w8/ andru/cgi-perl/civs/ results.pl?id=E_46442506716654dd. Accessed 17 June 2015.

Levy, Neil. 2003. Analytic and continental philosophy: Explaining the differences. Metaphilosophy 34 (3): 284-304.

McBurney, Peter, and Simon Parsons. 2001. Chance discovery using dialectical argumentation. In New frontiers in artificial intelligence: Joint JSAI 2001 workshop post-proceedings, ed. Takao Terano, Toyoaki Nishida, Akira Namatame, Syusaku Tsumoto, Yukio Ohsawa, and Takashi Washio, 414-424. Berlin: Springer.

Moyal-Sharrock, Danièle. 2005. Understanding Wittgenstein's on certainty. Basingstoke: Palgrave Macmillan.

Rescorla, Michael. 2009a. Shifting the burden of proof? Philosophical Quarterly 59 (234): 86-109.

Rescorla, Michael. 2009b. Epistemic and dialectical regress. Australasian Journal of Philosophy 87 (1): 43-60.

Sander, Thorsten. 2003. Beweislastverteilung und Intuitionen in philosophischen Diskursen. Journal for General Philosophy of Science 34 (1): 69-97.

Treanor, Brian. 2006. Slow university: A manifesto. http://faculty.lmu.edu/briantreanor/slow-university-amanifesto/. Accessed 17 June 2015.

van Eemeren, Frans H., and Rob Grootendorst. 1983. Speech acts in argumentative discussions: A theoretical model for the analysis of discussions directed towards solving conflicts of opinion. Dordrecht: Foris.

Walton, Douglas. 1992. After analytic philosophy, what's next?: An analytic philosopher's perspective. Journal of Speculative Philosophy 6 (2): 123-142.

Walton, Douglas. 2013. Methods of argumentation. Cambridge: Cambridge University Press.

Walton, Douglas. 2014. Burden of proof, presumption and argumentation. Cambridge: Cambridge University Press.

Walton, Douglas, and Erik C.W. Krabbe. 1995. Commitment in dialogue. Albany: SUNY Press.

Williamson, Timothy. 2011. Philosophical expertise and the burden of proof. Metaphilosophy 42 (3): 215-229.

Willoughby, Myrtle. 2012. Stoppism: Retrospects and prospects. Journal of Philosophy 109 (4): 281-294. 